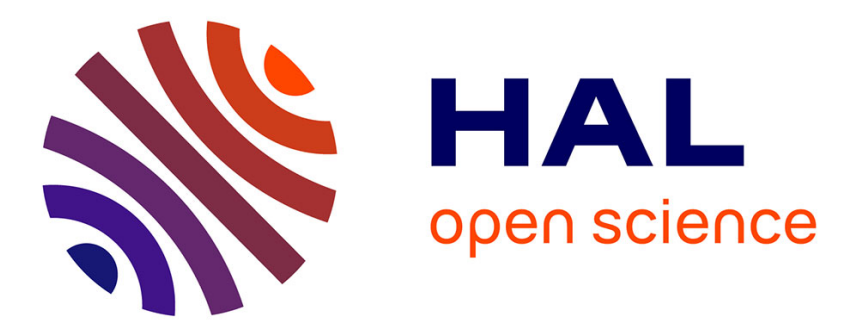

\title{
Application of progressive quadratic response surface method for an oscillation problem optimization
}

Xuan Hoa Nguyen, Jean-Louis Coulomb, Laurent Gerbaud, Jean-Christophe Crébier

\section{- To cite this version:}

Xuan Hoa Nguyen, Jean-Louis Coulomb, Laurent Gerbaud, Jean-Christophe Crébier. Application of progressive quadratic response surface method for an oscillation problem optimization. XI-th International Workshop on Optimization and Inverse Problems in Electromagnetism, Sep 2010, Sofia, Bulgaria. pp.ISBN 978-954-438-855-3. hal-00520046

\section{HAL Id: hal-00520046 https://hal.science/hal-00520046}

Submitted on 22 Sep 2010

HAL is a multi-disciplinary open access archive for the deposit and dissemination of scientific research documents, whether they are published or not. The documents may come from teaching and research institutions in France or abroad, or from public or private research centers.
L'archive ouverte pluridisciplinaire HAL, est destinée au dépôt et à la diffusion de documents scientifiques de niveau recherche, publiés ou non, émanant des établissements d'enseignement et de recherche français ou étrangers, des laboratoires publics ou privés. 


\title{
APPLICATION OF PROGRESSIVE QUADRATIC RESPONSE SURFACE METHOD FOR AN OSCILLATION PROBLEM OPTIMIZATION
}

\author{
H. NGUYEN XUAN, J-L. COULOMB, L. GERBAUD, and J-C. CREBIER \\ Grenoble Electrical Engineering Lab (G2ELab), UMR 5529 BP 46 - 38402 Saint-Martin-d'Hères Cedex, \\ FRANCE, Tel: +33 (0)4 7682 64 77/Fax: +33 (0)4 76826300 \\ E-mail: Hoa.Nguyen-Xuan@g2elab.grenoble-inp.fr, Jean-Louis.Coulomb@g2elab.grenoble-inp.fr, \\ Laurent.Gerbaud@g2elab.grenoble-inp.fr, jean-christophe.crebier@g2elab.grenoble-inp.fr
}

\begin{abstract}
The paper presents an effective optimization strategy applied in a physical structure optimization of a semiconductor Power MOSFET with expensive constraint computations. In order to deals with inaccuracy due to inevitable numerical errors in the objective function calculation (the power losses of the power MOSFET), the paper proposes to use the Progressive Quadratic Response Surface Method (PQRSM). The paper focuses on three aspects: the inevitable numerical errors in the power losses computation, the PQRSM principle, and finally the comparisons of several optimization methods on this problem.

Keywords: Genetic optimization algorithms, time step, Progressive Quadratic Response Surface Method, Power MOSFET, numerical error.
\end{abstract}

\section{INTRODUCTION: OBJECTIVE FUNCTION}

In our application, the computation of the objective function is based on a numerical method. The power losses of the power MOSFET within a period are calculated by adding the switching losses and conduction losses. The conduction losses are defined as in [5]. The switching losses are a sum of the losses at each switching on the operating period. So, a quasi static modelling is used, with complicated numericalanalytical expression, depending on a time step (timestep). The accuracy and the computation time of this numerical method are strongly sensible to this computation time step. The computation error creates oscillation on the objective function (see Figure 1). This numerical error also depends itself on the physical parameters
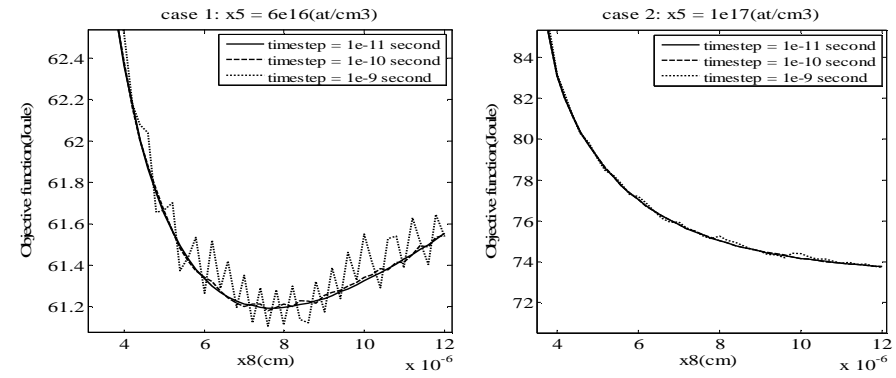

Figure 1. Objective function according to $x_{8}$ with 3 timestep values and two $x_{5}$ values in two cases

$X=\left[x_{1}, x_{2}, \ldots, x_{9}\right]$ (i.e. the time constants are influenced by $X$ )(see cases 1 and 2 in Figure 1). Therefore, without modifying the objective function calculation method, this oscillation is inevitable in the design optimization where the physical parameters are continuously changed, at each optimization iteration and each objective function calculation. In the design optimization, the objective function oscillation may lead to spurious local optimum [4] when a gradient-based optimization algorithm is applied. So, a first solution is to implement an adaptative computation time step, but it is yet time consuming. By observing (Figure 1) that the average value of the computed objective function (i.e., by removing the oscillations), is its good value, the paper proposes to use an approach based on Response Surface Approximation (RSA).

\section{PROGRESSIVE QUADRATIC RESPONSE SURFACE METHOD}

RSA has become an important tool in the design optimization to deal with high computational costs, numerical noise problems and numerical inaccurate gradient evaluations [1][2]. In this optimization problem, PQRSM has been chosen from [3]. PQRSM requires less sampling points to build a quadratic approximate function than conventional RSA. The PQRSM principle is detailed in [1][2][3]. The objective and constraint functions are approximated by quadratic functions (Eqn. 1) within a fair design space.

$$
f=c_{0}+\sum_{i=1}^{n} c_{i} \cdot x_{i}+\sum_{i=1}^{n} \sum_{j=i}^{n} c_{i j} \cdot x_{i} \cdot x_{j}, \text { where } n \text { is number of design variables; } x_{i} \text { and } x_{j} \text { are the design }
$$

variable; $c_{0}, c_{i}$ and $c_{i j}$ are the unknown polynomial coefficients.

PQRSM sequentially optimizes the approximate optimization problem in the context of the trust region model management strategy [3]. In this way, a model is defined to reduce the trust region at each iteration, around the solution carried out by optimization. This strategy is reapplied until the optimization problem converges. The trust region model management in [3] is difficult to adapt with the multidisciplinary design optimization problem. In our case, this model management is simplified. Each dimension of the design space is simply reduced by two (see Figure 2). This design space management will be detailed in the full paper. 


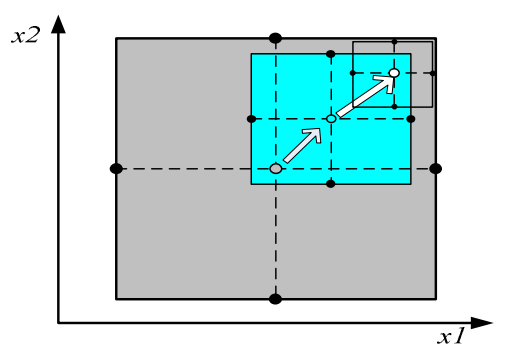

Optimal point at the 1 st iteration

Optimal point at the 2 th iteration

Optimal point at the 3 th iteration

$\square \quad$ Design space at the 1st iteration

ㅁ Design space at the 2 th iteration

$\square$ Design space at the 3 th iteration

Figure 2. Principle of the design space management with three iterations

\section{RESULTS AND DISCUSIONS}

\section{III.1 Optimization analysis}

In order to show the PQRSM principle, an optimization with three iterations is presented in this section. The optimization problem has 9 unknown parameters as shown in the Table 1 and several constraints.

Table 1. Unknown parameters analysis

\begin{tabular}{|c|c|c|c|c|}
\hline Parameters & initial design space & after $1^{\text {st }}$ iteration & after $2^{\text {nd }}$ iteration & after $3^{\text {rd }}$ iteration \\
\hline$x_{1} \cdot 1 \mathrm{e}-4$ & {$[20: 100]$} & $\mathbf{1 0 0}[60: 100]$ & $\mathbf{7 2 . 8 3}[60: 80]$ & $\mathbf{6 7 . 0 4}$ \\
\hline$x_{2} \cdot 1 \mathrm{e}-4$ & {$[20: 200]$} & $\mathbf{1 2 7 . 8 5}[65: 155]$ & $\mathbf{8 2 . 8 1}[65: 110]$ & $\mathbf{6 7 . 0 4}$ \\
\hline$x_{3}$ & {$[300: 3000]$} & $\mathbf{4 6 2}[300: 1650]$ & $\mathbf{1 6 5 0}[1312: 1988]$ & $\mathbf{1 9 8 8}$ \\
\hline$x_{4} .1 \mathrm{e} 19$ & {$[5: 15]$} & $\mathbf{1 0 . 7}[7,5: 12,5]$ & $\mathbf{9 . 8}[8.8: 12.0]$ & $\mathbf{1 0 . 1}$ \\
\hline$x_{5} .1 \mathrm{e} 16$ & {$[6: 20]$} & $\mathbf{1 0 . 1}[6: 13]$ & $\mathbf{7 . 0}[6: 9.5]$ & $\mathbf{6 . 7}$ \\
\hline$x_{6} \cdot 1 \mathrm{e}-4$ & {$[0,5: 1,4]$} & $\mathbf{1 . 0 4}[0,95: 1,4]$ & $\mathbf{1 . 2 3}[1.07: 1.29]$ & $\mathbf{1 . 1 8}$ \\
\hline$x_{7} \cdot 1 \mathrm{e}-4$ & {$[6: 8]$} & $\mathbf{6 . 9 2}[6,5: 7,5]$ & $\mathbf{7 . 0}[6.75: 7.25]$ & $\mathbf{6 . 8 7}$ \\
\hline$x_{8} \cdot 1 \mathrm{e}-7$ & {$[30: 120]$} & $\mathbf{8 2}[52: 98]$ & $\mathbf{7 5}[63: 87]$ & $\mathbf{6 3}$ \\
\hline$x_{9} .1 \mathrm{e}-4$ & {$[5: 15]$} & $\mathbf{1 0 . 9 8}[7,5: 12,5]$ & $\mathbf{1 0 . 0}[8.75: 11.25]$ & $\mathbf{8 . 7 5}$ \\
\hline Residual Approximation & & $\mathbf{3 2 8 . 1 8 7}$ & $\mathbf{0 . 0 1 7 3}$ & $\mathbf{1 . 2 3 e - 5}$ \\
\hline Objective Function & & $\mathbf{2 9 . 3 3}$ & $\mathbf{1 1 . 8 8}$ & $\mathbf{1 1 . 0 9}$ \\
\hline
\end{tabular}

After three iterations of PQRSM, the objective function value decreased from 29.33 to 11.09. The approximation of objective function is bad in the initial design space, but it is accurate in the next iterations when the design space decreased. So, an optimum is carried out after few iterations.

\section{III.2 Optimization Result}

In this section, some results of our power MOSFET design are presented. PQRSM and a genetic algorithm (Evolution Strategy (ES) [6]) are compared (see Table 2). After several optimizations by ES algorithm, the best solution is carried out with 600 generations, 40 children and 6 parents, 24000 function evaluations; while PQRSM converges after 8 iterations, 1152 function evaluations.

Table 2. Optimization result with PQRSM and ES algorithm(ng generation, nc chidren, np parents)

\begin{tabular}{|c|c|c|c|c|c|c|c|c|c|c|c|}
\hline Algorithm & $\begin{array}{c}x_{1} \\
.1 \mathrm{e}-4\end{array}$ & $\begin{array}{c}x_{2} \\
.1 \mathrm{e}-\end{array}$ & $x_{3}$ & $\begin{array}{c}x_{4} \\
4\end{array}$ & $\begin{array}{c}x_{5} \\
.1 \mathrm{e} 16\end{array}$ & $\begin{array}{c}x_{6} \\
.1 \mathrm{e}- \\
4\end{array}$ & $\begin{array}{c}x_{7} \\
.1 \mathrm{e}- \\
4\end{array}$ & $\begin{array}{c}x_{8} \\
.1 \mathrm{e}- \\
7\end{array}$ & $\begin{array}{c}x_{9} \\
.1 \mathrm{e}- \\
4\end{array}$ & $\begin{array}{c}\text { Objective } \\
\text { Function }\end{array}$ & $\begin{array}{c}\text { Calculation } \\
\text { time(minute) }\end{array}$ \\
\hline PQRSM & 52.86 & 52.7 & 2962 & 8.6 & 6.9 & 1.12 & 6.79 & 57 & 7.74 & $\mathbf{1 0 . 0 8}$ & $\mathbf{4}$ \\
\hline ES(ng=600,nc=40,np=6) & 52.17 & 52.2 & 3000 & 5.2 & 6.48 & 0.97 & 6.00 & 53.5 & 5.55 & $\mathbf{9 . 8 6}$ & $\mathbf{4 5}$ \\
\hline
\end{tabular}

In term of objective function value, the two algorithms give close results. But PQRSM is 11 times faster than ES algorithm. The parameter and sensibility analysis will be presented and discussed in the full paper.

\section{CONCLUSION}

In the paper, the Progressive Quadratic Response Surface Method is presented and applied to reduce the oscillation problem in the power losses computation of Power MOSFET as it carries out the optimization. The optimization results of PQRSM has been compared with the ES algorithm, with similar results but faster computation.

\section{REFERENCES}

[1] J. H. Choi et al. "Geometric and Electrical Optimization Design of SR Motor Based on Progressive Quadratic Response Surface Method" IEEE Trans. on Mag. , vol. 39, no. 5, pp. 3241-3243, september 2003.

[2] K. Park and S. Moon, "Optimal design of heat exchangers using the progressive quadratic response surface model", International Journal of Heat and Mass Transfer, vol. 48, no. 11, pp. 2126-2139, May 2005.

[3] J.F. Rodriguez, J.E. Renaud, B.A. Wujek and R.V. Tappeta, "Trust region model management in multidisciplinary design optimization", J. Comput. Appl. Math. , vol. 124, no. 1-2, pp. 139-154, December 2000.

[4] S. Hosder, L. T. Watson, B. Grossman, W. H. Mason, H. Kim, R. T. Haftka, and S. Cox, "Polynomial response surface approximations for the multidisciplinary design optimization of a high speed civil transport," Optim. Engrg, vol. 2, pp. 431-452, 2001.

[5] C. Hu, M. H. Chi, V. M. Patel "Optimum Design of Power MOSFETs" IEEE Trans. Elec. Dev., vol. ED-31, no. 12, December 1984

[6] P. Ivanov, K. Brandisky "Parallel implementation of evolution strategy optimization algorithm on multicore processors" COMPEL, vol. 28, no. 5, pp. 1129-1140, 2009. 